\title{
ANTEGRADE URETERIC STENTING IN MANAGEMENT OF URETERIC OBSTRUCTION IN CASE OF DIFFICULT RETROGRADE ACCESS; INDICATIONS, SUCCESS RATES \& PREDICTORS OF FAILURE
}

\author{
Khaled A. Taema', Hany H. Gad', Mohamed E. Ahmed ${ }^{1}$ and Amr M. Zriek ${ }^{2}$
}

1- Department of Urology, Ain Shams University, Cairo, Egypt; 2- Department of Urology, Ahmed Maher Teaching Hospital, Cairo, Egypt

Corresponding author Amr Mohamed Sayed Zriek Mobile: (+2) 01028405868

E.mail:

amr.zriek@yahoo.com

Received: $15 / 6 / 2021$

Accepted: 6/7/2021

Online ISSN: 2735-3540

\begin{abstract}
:
Background: Double $j$ (jj) routinely inserted cystoscopically in retrograde manner in managing various causes of ureteric obstruction. sometimes we face situations at which the jj failed to be inserted in such conventional route or carrying high degree of difficulty. antegrade jj can be successful alternative modality in managing such failures/ difficulties.
\end{abstract}

Aim of the work: Evaluate the antegrade ureteric stenting as an alternative to the retrograde ureteric stenting in the difficult cases of ureteric obstruction and to evaluate the predictors of success/failure of this procedure

Patients \& Methods: Prospective non-blinded interventional study that is conducted from the department of urology faculty of medicine Ain Shams University, Cairo, Egypt, between 2016 till 2020. included 78 patients with different causes of ureteric obstruction in two groups; group(I) included 28 patients with ureteric obstruction who had failed retrograde ureteric stenting; for them antegrade $j j$ stenting were tried \& group (II) included 50 cases of ureteric obstruction with high probability of difficulty or failure of retrograde stenting for them retrograde jj stenting tried first in 34 cases \& if failed retrograde stenting were tried, while antegrade stenting tried directly in 16 patients due to high patients vulnerability.

Results: In patients of group(I) antegrade stenting succeeded in 26 (92.86) patients \& failed in 2 (7.14) patients.in group (II) retrograde trial succeeded in (7) cases \& antegrade tried in (43) cases (27 cases after retrograde trial failure \& 16 cases tried from the start), antegrade stenting succeeded in 39 (90.7\%) cases \& failed in 4(9.3\%) cases. dye study e.g flow of dye to bladder showed statistically significant predictor of success/failure in both groups. most prevalent complications were hematuria in group(I) in (57\%) of the studied cases(hemoglobin drop didn't exceed $1 \mathrm{gm} / \mathrm{dl}$ \& hematuria subsided with genera measures) while in group (II) no complications occurred in (44\%) of cases. nephrostomy tube needed in(21\%) of cases in group (I) \& needed in (38\%) of cases in $\operatorname{group}(I I)$

Conclusion: Antegrade ureteric stenting is successful alternative in cases of failure of conventional retrograde stenting \& show high success rate in cases of high probability of difficulties.

Key words: Antegrade, Obstruction, Ureter, Double J 


\section{INTRODUCTION:}

Dilatation of the renal pelvis and calices as a result of urinary tract obstruction can be intrinsic or extrinsic and can result from both benign and malignant aetiologies. Extrinsic obstruction is most often caused by compression or mural infiltration of the ureter wall by a surrounding pelvic mass, for instance a urologic, gynaecologic or colorectal tumour. Furthermore, extrinsic obstruction can be caused by benign aetiologies such as retroperitoneal fibrosis, scar tissue, endometriosis, inflammation ${ }^{[1]}$. The treatment of choice in acute hydronephrosis is insertion of a percutaneous nephrostomy catheter (PCN). However, this external drainage catheter shows a high incidence of complications in long-term management, such as infection and dislocation ${ }^{[2]}$. alternatively, double $\mathrm{j}$ (jj) may be inserted retrogradely using cystoscope, however can be difficult or even impossible, especially in patients with obstructive malignancies ${ }^{[3]}$. Secondary uretero-enteric anastomosis stricture (UES) after urinary diversion ranges from 1 to $14 \%$ which is challenging in management either surgically or by conventional retrograde cystoscopic dj insertion due to altered anatomy ${ }^{[4]}$. In such cases the only options left are insertion of a percutaneous nephrostomy plus or minus an attempt at insertion of the ureteric stent by means of the ante-grade approach ${ }^{[1]}$.

\section{PATIENTS AND METHODS:}

\section{Patients:}

Total number of 78 patients of different causes of ureteric obstruction were studied from 2016 till 2020, in the department of urology, Ain shams university, Cairo,Egypt, patients included in two groups; group (I) included 28 patients of failed retrograde ureteric double $\mathrm{j}(\mathrm{jj})$ stenting of various causes of ureteric obstruction (see table 1 for causes) \& group (II) included 50 cases of high probability of difficulty/failure (no previous retrograde /antegrade trial) (see the following table (1) for causes).

Table (1): Causes of ureteic obstruction in both groups indicating insertion of double $\mathrm{j}(\mathrm{jj}$ )

\begin{tabular}{|c|c|c|c|c|c|c|}
\hline \multirow[t]{3}{*}{ Cause } & \multicolumn{4}{|c|}{ Groups } & \multirow{2}{*}{\multicolumn{2}{|c|}{ Chi-Square }} \\
\hline & \multicolumn{2}{|c|}{ Group I } & \multicolumn{2}{|c|}{ Group II } & & \\
\hline & $\mathrm{N}$ & $\%$ & $\mathrm{~N}$ & $\%$ & $\mathrm{X}^{2}$ & P-value \\
\hline CX*.bladder & 6 & 21.43 & 12 & 24.00 & 29.369 & $0.009 *$ \\
\hline CX.prostate & 4 & 14.29 & 10 & 20.00 & & \\
\hline CX.cervix & 2 & 7.14 & 4 & 8.00 & & \\
\hline CX.Endometrium & 2 & 7.14 & 0 & 0.00 & & \\
\hline CX.Colon & 1 & 3.57 & 0 & 0.00 & & \\
\hline Ureterovesical reimplantation & 3 & 10.71 & 6 & 12.00 & & \\
\hline Impacted upper ureteric stone & 2 & 7.14 & 2 & 4.00 & & \\
\hline UEAS $* *$ in ileal conduit & 0 & 0.00 & 7 & 14.00 & & \\
\hline UEAS in orthotopic bladder & 0 & 0.00 & 2 & 4.00 & & \\
\hline UEAS in sigma pouch & 0 & 0.00 & 1 & 2.00 & & \\
\hline Iatrogenic injury during hip external fixation & 0 & 0.00 & 1 & 2.00 & & \\
\hline Iatrogenic injury during laproscpoic hystrectomy & 0 & 0.00 & 2 & 4.00 & & \\
\hline Iatrogenic injury during URS & 0 & 0.00 & 3 & 6.00 & & \\
\hline Upper ureteric stricture & 3 & 10.71 & 0 & 0.00 & & \\
\hline Lower ureteric stricture & 5 & 17.86 & 0 & 0.00 & & \\
\hline Total & 28 & 100.00 & 50 & 100.00 & & \\
\hline
\end{tabular}

CX* : cancer UEAS**: uretero-enteric anastomotic stricture

Patients studied in the group (I) included $23(82 \%)$ male patients, while female patients were 5 patients $(17 \%)$. In group (II) male patients were 38 (76 \%) while females were $12(24 \%)$. As regard the age in group (I) mean age was 
48.321 \pm 13.303 ranging from $18-31$ years. In group (II) mean age was 52.020 \pm 8.665 ranging from 23-64 years. For the body mass index (BMI) in group (I) the average was $25.321 \pm 3.255$ ranging from $18-31$ and in group (II) the average was $27.160 \pm 3.046$ ranging between $20-33$.

\section{Design:}

In group (I) 28 trail of antegrade ureteric stenting tried due to failure of retrograde cystoscopic insertion of double $\mathrm{j}$. while in group (II) antegrade ureteric stenting done directly i.e trial of retrograde ureteric stenting skipped in 16 patients due to patient vulnerability \& recorded high failure rate (10 cases of urinary diversions with uretero-entertic anastomotic strictures) or complicated situations (6 cases of iatrogenic injury), the remaining 34 cases of group (II);retrograde ureteric stenting tried first then antegrade double $\mathrm{j}$ (jj) ureteric stenting tried in the failed cases.

All patients had informed consent, full laboratory investigations, preoperative imaging enough to diagnose the causes, level \& degree of obstruction. If not contraindicated patients had intravenous urography study(alternatively antegrade pyelogram if there was nephrostomy tube inserted preoperatively) to identify the flow of dye distal to obstruction to the bladder, presence of kinks along the ureter $\&$ the length of the ureteric obstructed segment; those findings were evaluated as predictors of success /failure of the procedure.

Patients also had preoperative anesthesiological evaluation \& received preoperative antibiotic prophylaxis.
Success rates recorded, and the parameters of the dye study are plotted against the success and failure rates as predictors of success or failure, operative time and hospital stay were recorded. renal function tests were done \& compared to preoperative ones, patients followed up for early complications postoperatively during hospital stay \& one week post discharge

Approval had obtained from the ethical committee at Ain shams University before starting the research.

This study aimed to evaluate the antegrade ureteric stenting as alternative to failed cases of reterograde ureteric stenting in the included cases of the study and to study the predictors of success /failure of the antegrade ureteric stenting.

\section{Technique:}

Anesthesia mainly done using spinal anesthesia in group (I) (78\%) in 22 patients $\&$ in 48 patients in group (II) $(96 \%)$, only in 6 patients $(21 \%)$ in group (I) $\&$ in 2 patients $(4 \%)$ in group (II) general anesthesia needed.

Patients positioned in Galdako modified Valdavia position position(GMV) (ipsilateral lower leg in extension and the other in flexion) (see figure 1). The procedure mostly done by a surgeon \& assistant (one surgeon who performs the antegrade approach and the assistant surgeon who deals with retrograde endoscopy) \& Mostly, there are two scrub nurses.

Mobile C-arm unit is in front of the surgeon performing the procedure with ultrasound device (3.5 MHz transducer) is beside the patient, on the side of the targeted kidney. 

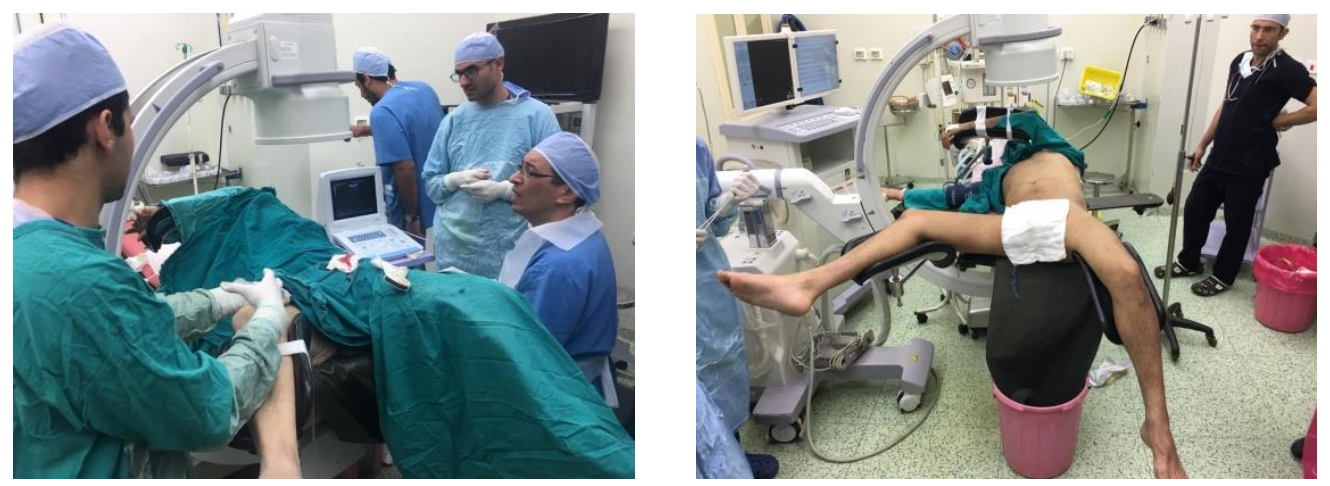

Figure 1: Patient positioning \& operative room setup

The procudre starts after prepping and drapping the targeted kidney by Opacification of the pelvicaliceal system either by Intraoperative intravenous urography or mostly by Ultrasonography guided puncture follow by antegrade pyelogram. "Seldinger technique".

Choosing appropriate puncture \&passing hydrophyllic 0.035 inch guide

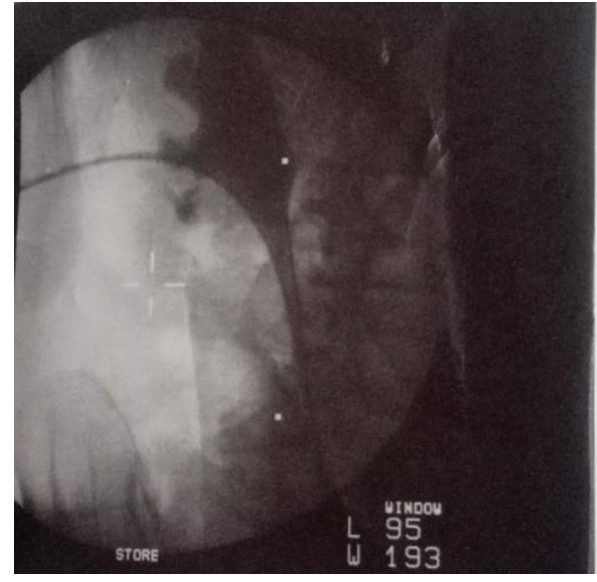

a wire (Terumo glidewire) as working guidewire through ureteropelvic junction will be done preferentially through a mid or upper pole calyx because it provides a more favorable angle to the ureter than the lower pole calyx. another guidewire left during the whole procedure as safety guidewire. (see figure 2)

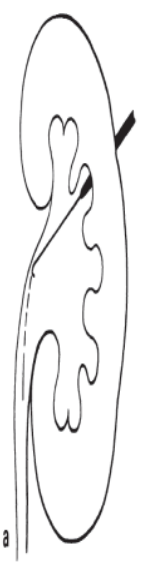

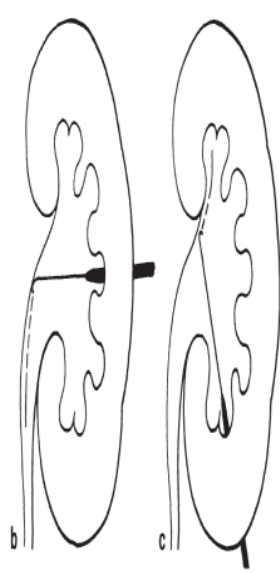

b

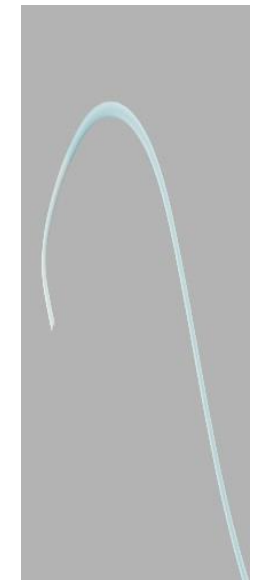

c

Figure 2: a, b: calyx puncture preferentially done through upper or middle calyx. c: multipurpose angiography catheter (MPA); cobra head catheter.

Manipulation of obstacles precluded retrograde access using multipurpose angiography catheter (cobrahead catheter) (see figure 2) followed by Guidewire retrieval from the bladder/pouch of diversion and ureteric stenting will suffice the procedure (see figure 4).

Once the wire is out to the bladder providing through and through rail road access ("body floss" technique) tension should be maintained on both ends of the wire and a retrograde catheter can be advanced through the bladder to form the loop within the renal pelvis.

Many maneuvers were applied to overcome the obstructed segment during the procedure; If resistance is encountered because of angulations, a catheter should be advanced to the level of the obstacle and dilute contrast injected to outline the ureteral 
path. A slightly curved tip catheter can be used (usually a multipurpose catheter- MPA) in combination with a variety of guide wires in order to pass the obstacle) (figure 3). Also Change in patient respiratory effort will sometimes alter the degree of angulation sufficiently for successful catheterization (figure 3), also for straitening the kinked ureter antegrade ballon dilator may be passed and inflated above the kink then slight upward traction will help to overcome minor kinks and straightening the ureter (not illustrated). Resistance secondary to stricture or fistulas requires a few extra steps, A catheter is introduced to the level of the obstacle and dilute contrast injected to map the ureteral course. The slightly curved tip catheter is positioned about $1 \mathrm{~cm}$ above the obstacle and a floppy tip guide wire is inserted. Rotation of the catheter while gently probing allows the guide wire to approach the stenoses at a multiplicity of angles until the opening is located. It is even possible to use this technique successfully in ureters which are not opacified beyond the obstruction.(figure 3)

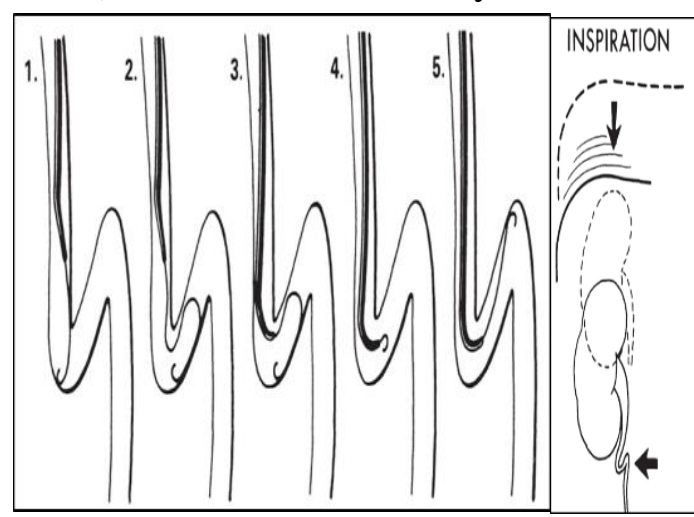

a

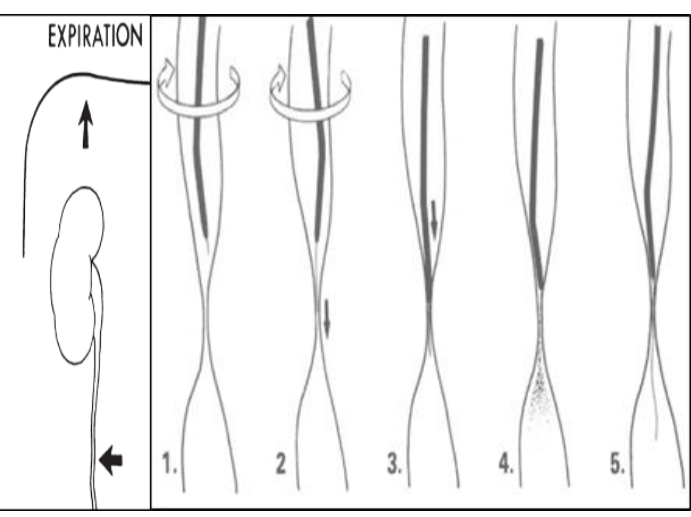

b c

Figure 3: Different manouveurs may be used to bypass kinks or stenotic segment during the antegrade stenting; from left to right: a: advancing the guidewire through a angled tip ureteric catheter, $b$ : advancing the guidewire while changing the respiratory effort of the patient \&c: torqueing movement of the guidewire through stenotic segment.

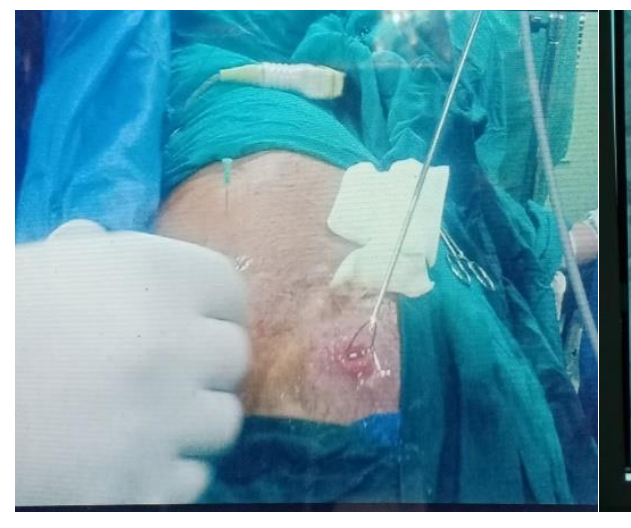

a

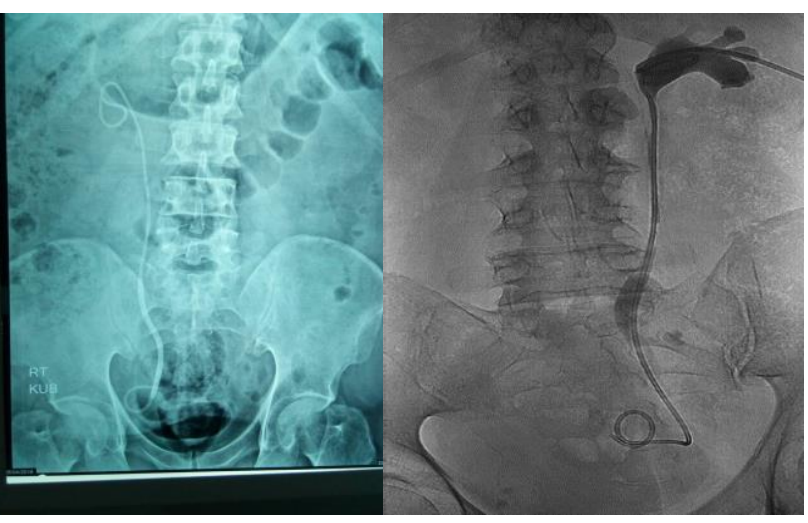

b

c

Figure 4: a \& b guidewire retrieval from stoma of ileal conduit after antegrade manipulation of 2ry uretero-enteric anastomotic stricture following urinary diversion \& double girth double $\mathrm{j}$ in the conduit after insertion, c radiograph after antergrade ureteric stenting after ureteric injury during URS.

In face of bladder mass occluding the ureteric orifice reduction of the mass through trans uretheral resection of the bladder tumor (TURBT) used to cut over the pointing (probing) ureteric orifice allowing its retrieval. Also, antegrade methylene blue 
dye could be injected antegradely to localize the orifice.

Similarly in cases of prostatic carcinoma obstructing or displaying the ureteric orifice transuretheral resection of prostatic tissues (TURP) were done, this was applied too incase if the prostatic mass obstructing the entery to the prostated if not already done through the primary failed retrograde tiral.

Covering nephrotomy ma be left at the end of the procedure depending on the intraoperative complications (extravasation or bleeding) \& left for 2 days.

At the end of each procedure, success or failure recorded and technical causes leading to failure studied, dye study preoperativey \& intraoperarive pyelogrm analysed for predicting the success/failure of the procedure.intaoperative complications \& early post-operative compliations studied.

\section{RESULTS:}

In group (I) where 28 failed retrograde ureteric stenting were given trial of antegrade ureteric stenting, the procedure succeeded in $26(92.86 \%)$ patients \& failed 2 (7.14\%) patients. in group (II) with cases of suspected difficulties / failure, retrograde trial of stenting succeeded in 7 patients out of the 50 leaving 43 patient in this group, of total antegrade stenting succeeded in 39 patients $(90.7 \%)$ while failed in 4 patients (9.3\%).(diagram 1)

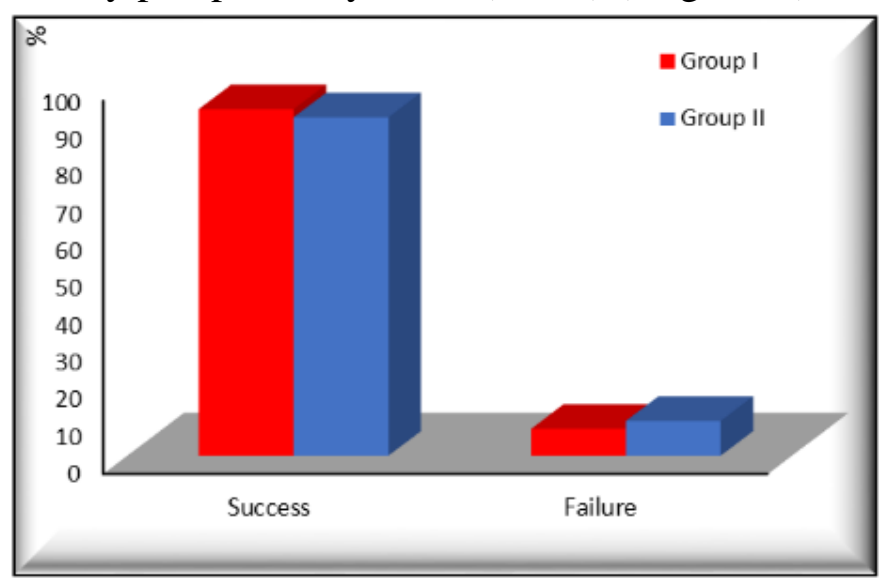

Diagram 1: success rates of both groups

In group II of total number of cases 43 , antegrade stenting tried directly in 16 patients; of them it succeeded in 14 patients $(87.5 \%) \&$ failed in 2 patients only (12.5\%),in 27 patients where the initial retrograde stenting failed, the antegrade succeeded in 25 patients $(92.5 \%) \&$ failed in patients $(7.4 \%)$.(diagram 2 )

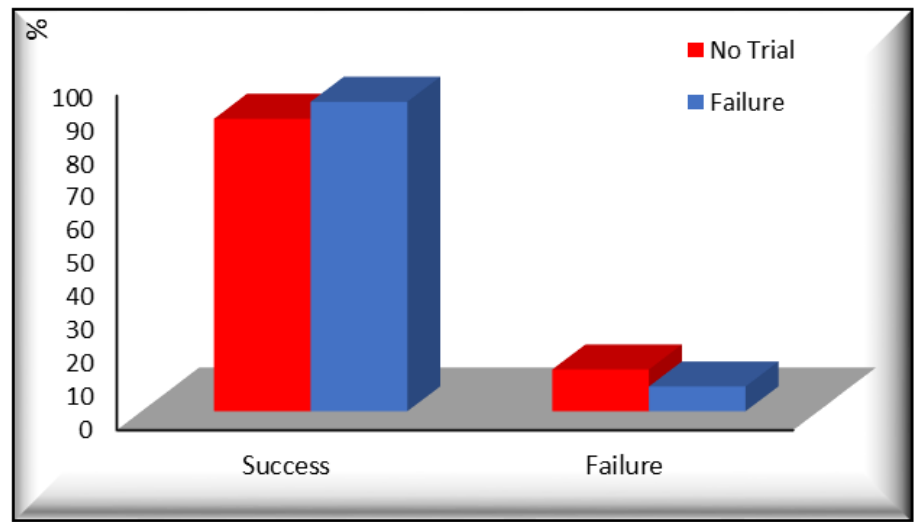

Diagram 2: Success rates in group II 
Antegrade dye study in group I evaluated in each patient in trial to predict the possible patterns that predict success/failure of antegrade stenting, dye flow to the bladder beyond the obstruction found in 21 succeeded antegrade stenting $(80.8 \%)$ while no dye flow found in failed cases, length of obstructed segment $<1 \mathrm{~cm}$ found in association of success of antegrade stenting in 22 cases $(84.6 \%)$, yet if $>1 \mathrm{~cm}$ was found only in 15.4 $\%$ of succeeded cases, as regard to presence or absence of extravasation or kinks; there was no extravasation nor kinks in $96.15 \%$ of succeeded cases. (Table 2)

Table (2): Dye study and its value as predictor of success /failure for antegrade ureteric stenting in group I

\begin{tabular}{|c|c|c|c|c|c|c|c|}
\hline \multicolumn{2}{|l|}{ Group I } & \multicolumn{4}{|c|}{ AGJJ s /f } & \multirow{2}{*}{\multicolumn{2}{|c|}{ Chi-Square }} \\
\hline & & \multicolumn{2}{|c|}{ Success } & \multicolumn{2}{|c|}{ Failure } & & \\
\hline & & $\mathrm{N}$ & $\%$ & $\mathrm{~N}$ & $\%$ & $\mathrm{X}^{2}$ & $\mathrm{P}$-value \\
\hline \multirow[t]{2}{*}{ Flow of dye to bladder } & No & 5 & 19.23 & 2 & 100.00 & \multirow[t]{2}{*}{6.462} & \multirow[t]{2}{*}{$0.011^{*}$} \\
\hline & Yes & 21 & 80.77 & 0 & 0.00 & & \\
\hline \multirow[t]{2}{*}{ Length of obstructed segment } & $<1 \mathrm{~cm}$ & 22 & 84.62 & 1 & 50.00 & \multirow[t]{2}{*}{1.517} & \multirow[t]{2}{*}{0.218} \\
\hline & $>1 \mathrm{~cm}$ & 4 & 15.38 & 1 & 50.00 & & \\
\hline \multirow[t]{3}{*}{ Extravasation/kink } & No & 25 & 96.15 & 0 & 0.00 & \multirow[t]{3}{*}{20.462} & \multirow[t]{3}{*}{$<0.001 *$} \\
\hline & Extravasation & 0 & 0.00 & 1 & 50.00 & & \\
\hline & Kink & 1 & 3.85 & 1 & 50.00 & & \\
\hline
\end{tabular}

As regard the dye study in group II dye flows to the bladder in 37 cases of succeeded cases $(94.9 \%)$ \& no dye passed to bladder in $75 \%$ in failed cases ( 3 patients), on reviewing the results concerning the length of the obstructed segment, the length was <

Table (3): Dye study and its value as predictor of success /failure for antegrade uretertic stenting in group II*

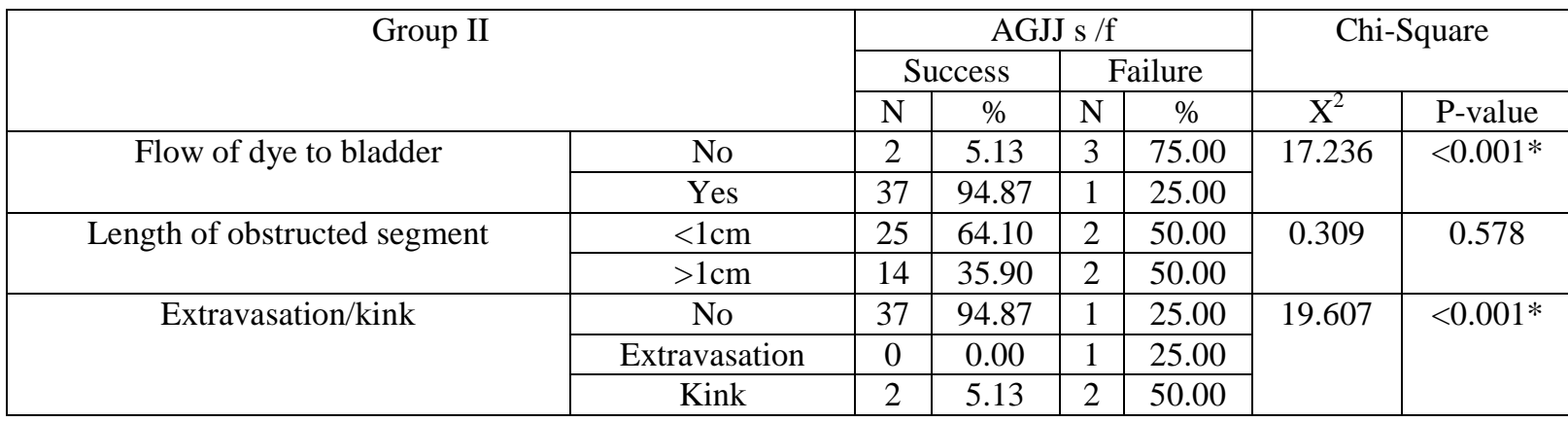

No auxiliary procedures needed 19 patients $(67 \%)$ in group I \& 27 patients $(54 \%)$ in group II, TURBT needed in no patients in group I \& in 2 patients $(4 \%)$ in group II, TURP was done in 2 patients $(7 \%)$ in group I \& 1 patient $(2 \%)$ in group II, nephrostomy tube being the most commonly done auxiliary procedure in both groups as in 6 patients (21\%) in group I \& $19(38 \%)$ in group II, Endopeotmy done in 1 patients (3\%) in group I \& redo antegrade stenting was done in only 1 patient $(2 \%)$ in group II.
$1 \mathrm{~cm}$ in $25(64 \%)$ of succeeded cases \& > $1 \mathrm{~cm}$ in $14(35 \%)$ of failed cases, finally; absence of extravasation /kinks found in 37 (94.9\%) of antegrade successful cases \& present in $3(75 \%)$ of antegrade failed cases. (Table 3) 
minutes) \& those patients stayed at hospital for mean days of $1.750 \pm 0.645$ (range: 1-3 days), in group II mean operative time was 64.800 29.606 minutes (range 30-120 minutes) \& those patients stayed with mean days of $1.880 \pm 0.689$ (range: $1-3$ days).

The mean preoperative serum creatinine $1.929 \pm 0.562 \mathrm{mg} / \mathrm{dl}$ (range: $1.1-3.7 \mathrm{mg} / \mathrm{dl}$ ) which dropped to mean of $1.646 \pm 0.514$ $\mathrm{mg} / \mathrm{dl}$ (range: $1-3.5 \mathrm{mg} / \mathrm{dl}$ ), in group II preoperative serum creatinine with mean of $2.130 \pm 0.641 \mathrm{mg} / \mathrm{dl}$ (range: $1.1-3.5 \mathrm{mg} / \mathrm{dl}$ ) dropped postoperatively to mean of $1.858 \pm 0.629 \mathrm{mg} / \mathrm{dl}$ (range: $1-3.5 \mathrm{mg} / \mathrm{dl}$ ).

\section{DISCUSSION:}

Danilovic et $a .^{[5]}$. evaluated the likelihood of retrograde double-J stenting in urgent ureteral drainage according to obstructing pathology. Showing that the Retrograde double-J stenting failed in $9 \%$ $(2 / 22)$ of intrinsic obstruction and in $52 \%$ (13/25) of extrinsic obstruction caused by pelvic malignancies, bladder mass or prostatic carcinoma.

The incidence of secondary ureteroenteric anastomosis stricture (UES) after urinary diversion ranges from 1 to $14 \%$ which is challenging in management either surgically or by conventional retrograde cystoscopic $\mathrm{dj}$ insertion due to altered anatomy ${ }^{[4]}$. Ureteroenteric anastomotic strictures may be difficult to treat following urinary diversion. Since many patients undergoing surgery have bladder cancer and may require treatment with nephrotoxic chemotherapeutic agents, it is important to preserve functioning renal tissue to as great an extent as possible ${ }^{[6]}$. Endourological management of ureteroenteric anastomotic strictures appears to be the most appropriate initial approach, since this is likely to lead to shortened hospitalization, and decreased costs and morbidity ${ }^{[7]}$.

Gynecologic procedures account for the majority of ureteral injuries with $64 \%-82 \%$, while colorectal, vascular pelvic, and urologic surgery account for approximately $15 \%-26 \%$ and $11 \%-30 \%$, respectively ${ }^{[8]}$. Urologic interventions including ureteroscopy, lympha-denectomy, and urinary diversion account for up to $13 \%$ or ureteral injury and strictures. Most commonly they are attributed to endoscopic procedures that involve stone treatment ${ }^{[9]}$. Koukouras et al. [10] showed successful antegrade double $\mathrm{j}$ stenting in management of 18 out of 25 patients $(72 \%)$ with iatrogenic injuries such as ureteral laceration and ureteral obstruction by.

In our study we included 78 patients of different pathologies indicated for double $\mathrm{j}$ ureteric stenting, the pathologies can be categorized as malignant ureteric obstruction with total number of 41 cases as follow; cancer bladder 18 , cancer prostate 14 ,cancer cervix 6,cancer endometrium 2 and cancer colon 1, while non-malignant ureteric obstructions included the rest of patients as follow; obstruction due to impacted upper ureteric stones 4; strictures after uretero-vesical reimplantation 9,uppe ureteric strictures 3, lower ureteric strictures 5 and nonmalignant ureteric obstruction after urinary diversions 10 (7 cases after ileal conduit, 2 after orthotopic bladder and 1 case after urtero-sigmoid anastomosis). finally this study included 6 cases of ureteric iatrogenic injury 1 case after iatrogenic ureteric injury during hip external fixation, 2 cases of iatrogenic ureteric injury during laparoscopic hysterectomy and 3 cases following ureterorenoscopy (URS).

In cancer bladder patients; 5 patients were non muscle invasive \& 13 were muscle invasive, the non-muscle invasive cases the mass were in proximity to the ureteric orifices in whom resection were done and subsequent ureteric obstruction occurred, in the 13 patients with muscle invasive bladder mass the invasion of the ureteric orifice occurred as the pathology was advanced to the ureter for those patients nephrostomy 
tube was inserted and adjuvant /palliative chemo/radiotherapy started, later on patients were evaluated and included for tiral of antegrade ureteric insertion.

Van der Meer et al. ${ }^{[11]}$, studied 100 patients, Most prevalent indications for a double $\mathrm{j}$ stent was obstructive ureteral pathology due to malignancy $(\mathrm{n}=63)$, stricture $(n=30)$, or stones $(n=12)$.

Liatsikos et al. ${ }^{[12]}$ reported their longterm experience with palliative-treatment for extrinsic malignant obstruction with percutaneous placement of antegrade metal stents. A total of 119 ureters were managed. Success rate reached $100 \%$.

Watson and Patel ${ }^{[13]}$ evaluated the success rate of primary ante-grade ureteric stenting in 38 patients (50 ureters) with obstructive hydronephrosis, of acute or chronic onset and of benign/malignant origin. Forty out of fifty $(80 \%)$ ureters were considered primary stent successes.

Hausegger and Portugaller ${ }^{[1]}$ reported their experience with regard to insertion of percutaneous nephrostomy and placement of ante-grade ureteric stenting a with a success rate of more than $90 \%$.

In this study, In group (I) where 28 failed retrograde ureteric stenting were given trial of antegrade ureteric stenting, the procedure succeeded in $20(71 \%)$ patients \& failed $8(28 \%)$ patients. the failed 8 cases were; (1) case due to bladder mass invading the right ureteric orifice causing marked backpressure for which nephrostomy tube inserted and the patient had chemotherapy before radical cystectomy, (2) cases due to prostatic carcinoma altering the anatomy and for them nephrostomy tubes were inserted till definitive management, (1) case due to stricture following ureterovesical reimplanation for which nephrostomy tube inserted and open repair was done, 1 case due to upper ureteric stricture due to long standing stone for which urterolithotomy and dj was inserted surgically \& 3 cases due to lower ureteric stricture due to bilharsiasis for them ureterovesical reimplantation was done.

While in group(II) with cases of susprected difficulties/failure, antegrade stenting succeeded in 30 cases $(69 \%) \&$ failed in 13 cases $(30 \%)$ those failed cases were as follow; (2) cases due to bladder mass invadine the ureteric orifices for them nephrostomy tubes were inserted prior to definitive management, (2) cases due to lower ureteric stricture following radiotherapy for prostatic carcinoma and 1 case due to prostatic cancer distorting the bladder anatomy, (1) case of cancer cervix extrinsically compressing the ureter, (1) case due to stricture following ureterovesical reimplanation, (1) case due to impacted upper ureteric stone, (2) cases in ureterointestinal anastomotic stricture after ileal conduit urinary diversion, (1) case of iatrogenic injury following hip external fixation \& (1) case following iatrogenic injury of the ureter during laparoscopic hysterectomy.

In group (II); in the "retrograde no trial cases " (16) cases the antegrade succeeded in 12 cases (75\%) and failed in 4 cases $(25 \%)$. While in the rest of retrograde failed cases (27) the antegrade succeeded in 18 cases $(66 \%)$ and failed in 9 cases $(33 \%)$.

In both groups the technical causes of retrograde failure included the following, no ureteric orifice could be identified during the cystoscopy in (30) cases, guide wire didn't pass ureteric stricture in (11) cases, guide wire didn't pass stone impaction in (4) cases, guide wire couldn't manipulate difficult direction in (7) cases \& guide wire couldn't pass kinks in (3) cases.

Lu et al. ${ }^{[14]}$ reviewed fifty consecutive per-cutaneous ureteric stent insertions in 40 patients. They reported that: Thirty seven of 50 cases were performed following failed retrograde-stenting. Ante-grade stenting failed in two out of $37(5 \%)$ of cases of 
malignant obstruction, and four out of 13 $(31 \%)$ cases of benign ureteral disease. Causes of failure and common technical problems included poor angulation of the per-cutaneous track, tortuous dilated ureters, tight obstruction, wedging of stent assembly components due to high resistance, and difficulty in positioning of the proximal pigtail.

One of the most important additive data in this study is focusing on the dye study patterns as predictor of success/failure of the procedure independent on the pathology itself, For predicting the success / failure; dye study are evaluated in 3 aspects in each case those aspects include; flow of the dye to the bladder beyond the obstructed segment, length of the obstructed segment \& presence or absence of extravasation or kinks.

Accordingly in evaluation of value of dye study pattern as predictor of success/failure of antegrade stenting in group I \& II; flow of dye to the bladder beyond the obstructed segment $\&$ absence of extravasations /kinks showed statistically significant difference as predictor of success/ failure of the antegrade stenting, while the length of obstructed segment showed no statistical significance in predicting the success/ failure in both groups.

Watson and Patel ${ }^{[13]}$ evaluated the success rate and cost efficiency of primary ante-grade ureteric stenting in 38 patients (50 ureters) with obstructive hydronephrosis concluded that: In carefully selected patients, the majority of obstructed ureters can be primarily stented using simple equipment. The reduced hospital stay and over-all success rate significantly improves the cost competitiveness of antegrade ureteric stent insertion.

In this study mean operative time in group I was $61.250 \pm 16.137$ minutes (range: 30-90 minutes) \& those patients stayed at hospital for mean days of $1.750 \quad \pm 0.645$ (range: 1-3 days), in group II mean operative time was $64.800 \pm 29.606$ minutes (range 30 120 minutes) \& those patients stayed with mean days of $1.880 \pm 0.689$ (range: $1-3$ days).

Rao et al. ${ }^{[15]}$ performed a retrospective audit of 165 ante-grade double $\mathrm{J}$ (JJ) ureteric stent insertions. They reported five (3\%) patients, with silent ureteric perforation and an extra-anatomic placement of ureteric stent with delayed retroperitoneal abscesses, a pelvic urinoma \&concluded that: Antegrade ureteric double $\mathbf{J}$ stenting is a procedure which is not without complications.

Borelli Palanca et al. ${ }^{[16]}$ reported 27 ante-grade ureteric stent (double J) insertions \& achieved a $90 \%$ success rate. A case of peri-renal hematoma occurred after insertion of nephrostomy and this was the only relevant complication they encountered. They concluded that ante-grade ureteric stent insertion is a good alternative which, under several circumstances, the conventional retrograde insertion of ureteric stent fails.

Kim and Park ${ }^{[17]}$ evaluated seven patients who underwent ante-grade ureteric stent insertion \& reported that: Double-J ureteric stent was successfully placed in all seven patients Complications included abdominal/flank pain $(\mathrm{n}=7)$, visible hematuria $(\mathrm{n}=5)$, and elevated blood pressure $(n=1)$. All the complications were relieved within three days after the procedure and conservative management.

Talking about this study The overall incidence of complications in group I is (71 $\%$ ) in 20 cases between mild to moderate hematuria without significant impact on hematocrit and resolved with fluids and usual ant hemorrhagic medications. extravasation in 4 cases which didn't affect the procedure and were managed by postoperative antibiotics and follow up with covering nephrostomy tube in 2 cases 
removed after 3 days, in group II the overall incidence of complications were $(56 \%)$ in 28 cases as follow; non-significant hematuria in 18 cases, extravasation in 9 cases; 3 of them needed covering nephrostomies removed after 2-3 days, in 1 case the dj slipped 1 week postoperatively for which redo the procedure was done. It should be noted that in group II there were 7 cases at which retrograde stenting succeeded showing no complications which slightly diluted the overall incidence of complications in group II.

\section{Conclusions:}

Our results of success as regard of antegrade double $\mathrm{j}$ stenting are promising, with acceptable range of complications, if to criticize our study is the 1-wide range of pathologies which could be justified by the paucity of studies about the antegrade double $\mathrm{j}$ stenting although its well-known procedure, so those bunch of pathologies can open away for separate studies of each pathology.2-also randomization between antegrade \& retrograde stenting is not justified with superiority \& feasibility of the conventional retrograde cystoscopic insertion. 3-in face of some patients vulnerability \& complicated situations (patients with uretero-enteric anastomotic strictures after urinary diversion \& patients with iatrogenic injury) we preferred to go directly for antegrade stenting especially in those with solitary kidney or border line serum creatinine or in patients can't tolerate the longer anesthesia time or can't be positioned in lithotomy.

Based on our primary experience, antegrade double $\mathrm{j}$ insertion was not only successful alternative way in case of failed retrograde access but also it gives higher success rate where difficulties of retrograde stenting may be suspected, justified by superiority as regard time consumed, regional or spinal anesthesia.
Antegrade double $\mathrm{j}$ stenting is appealing in some situations e.g malignant ureteric obstruction caused by pelvic malignancies \& 2ry strictures in the uretro-enteric anastomosis following urinary diversion.

Preoperative \& intraoperative dye study can be used to predict the success/failure of the procedure.

Antegrade double $\mathrm{j}$ is not without complications but all are within the common endourolgical complications \& can be managed conservatively.

Antegrade double $\mathrm{j}$ stenting is easy procedure to be learnt \& every urologist is familiar with its equipment's.

We recommend that not every urology department staff shall master it, but one team can save the others.

\section{REFERENCES:}

1. Hausegger KA and Portegaller $\mathrm{H}$ R. Percutaneous nephrostomy and ante-grade ureteral stenting: technique - indications complications. Eur Radiol. 2006; 16(9): 2016-2030.

2. Venyo A and Bakir E. Antegrade Ureteric Stenting Prospective Experience in Managing 30 Patients; Indications; Complications And Outcome, Webmed Central urology. 2011; 2(1): 42.

3. 3-Yossepowitch O, Lifshitz DA, Dekel Y, Gross M, Keidar DM, Neuman M, Livne PM, Baniel J. Predicting the success of retrograde stenting for managing ureteral obstruction. J Urol 2001; 166:1746-1749.

4. Meretyk S, Clayman RV, et al. "Endourological treatment of ureteroenteric anastomotic strictures: longterm followup." J Urol 1991; 145(4): 723-727.

5. Danilovic A, Ioannis MA, Jose LM, Antonio ML. likelihood of retrograde double $\mathrm{j}$ stenting according to ureteral obstructing pathology. International Braz $\mathbf{J}$ Urol. 2005; 31(5);431-436. 


\section{Khaled A. Taema, et al.,}

6. Vandenbroucke F, Van Poppel H, Vandeursen H, Oyen R and Baert L. Surgical versus endoscopic treatment of nonmalignant uretero-ileal anastomotic strictures. Brit. J. Urol., 1993; 71: 408.

7. Kramolowsky EV, Clayman RV and Weyman PJ. Management of ureterointestinal anastornotic strictures: comparison of open surgical and endourological repair. J. Urol., 1988; 139: 1195.

8. Elliott SP and McAninch JW. Ureteral injuries: external and iat-rogenic. Urol Clin North Am 2006; 33:55-66.

9. Abboudi H, Ahmed K, Royle J, Khan MS, Dasgupta P, N'Dow J. Ureteric injury: a challenging condition to diagnose and manage. Nat Rev Urol 2013; 10:108e15.

10. Koukouras D, Petsas T, Liatsikos E, Kallidonis P, Sdralis EK, Adonakis G, et al. Percutaneous minimally invasive management of iatrogenic ureteral injuries. J Endourol 2010; 24: 1921-7.

11. van der Meer RW, Weltings S, van Erkel AR, RoshaniaH, Elzevier HW, van Dijk LC et al. Antegrade Ureteral Stenting is a Good Alternative for the Retrograde Approach. Curr Urol. 2017; 10(2):87-91
12. Liatsikos EN, Karnabatidis D, Katsanos K, Kallidonis P, Kadgadis G C, Christeas N, et al. Ureteral metal stents: 10-yearexperience with malignant ureteral obstruction treatment. J Urol. 2009; 182(6): 2613-2617.

13. Watson GM and Patel U. Primary antegrade ureteric stenting: prospective experience and cost-effectiveness analysis in 50 ureters. Clin Radiol. 2001; 56(7): 568574.

14. Lu DS, Papanicolaou N, Girad M, Lee MJ, Yuder IC. Percutaneous internal ureteral stent placement: review of technical issues and solutions in 50 consecutive cases. Clin Radiol. 1994; 49(4): 256-261.

15. Rao AA, Alleemudder A, Mukeril G, Mishra V, Motiwala H, Chari M, et al. Extra-anatomical complications of antegradedouble-J insertion. Indian $\mathrm{J}$ Urol. 2011; 27(1): 19-24.

16. Borelli Palanca A, Ferrer Puchol M D, Villamón Fort R, Gil Romero J. Anterograde insertion of ureteral catheter. Actas Urol Esp. 2000; 24(3): 243-247.

17. Kim BM and Park S I. Placement of double-J ureteric stent using the pullthrough technique in patients with tight ureteric stents. Abdom Imaging. 2008; 33(2): 227-240. 
تدعيم الحالب في الاتجاة المتقام لعلاج انسداد الحالب في حالة صعوبة تدعيمة في الاتجاة المتراجع، الاسباب، معدلات النجاح والعوأمل التنبوئة للفشل فئل

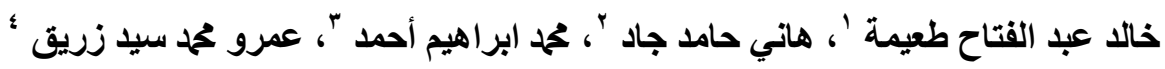

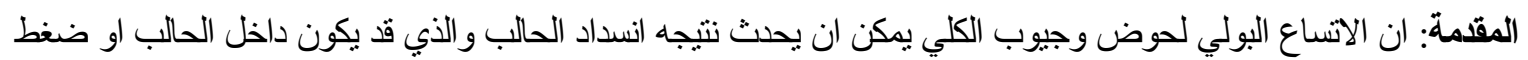

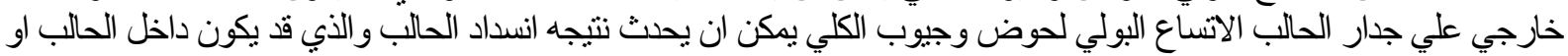

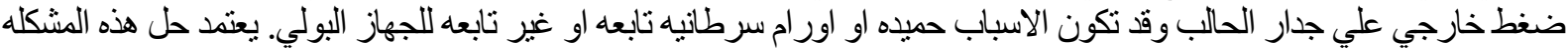

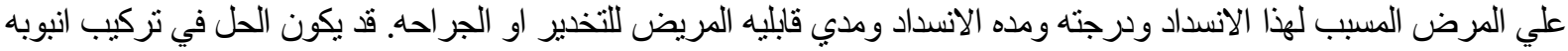

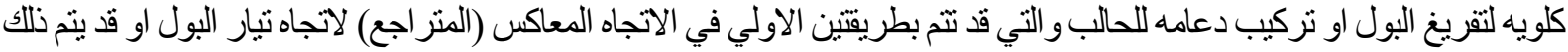

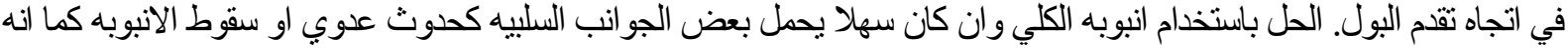

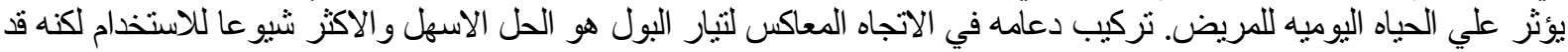

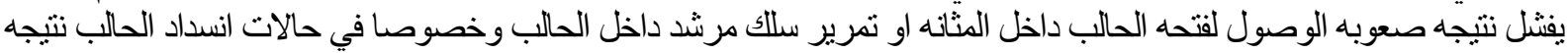

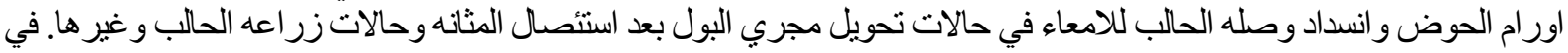

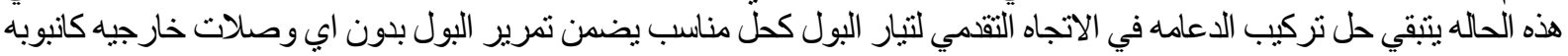

الهـف من البحث: دراسة امكانية تدعيم الحالب في اتجاة المتقدم لعلاج انسداد الحالب في حالة صعوبة تدعيمة في

الاتجاة المتر اجع ودر اسة العو امل التنبؤية للفنّل

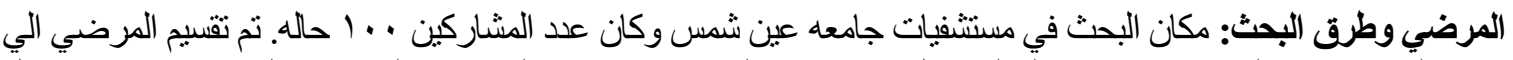

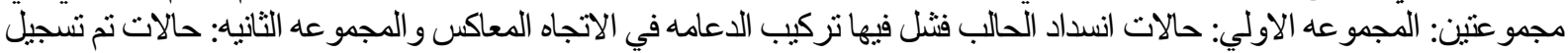

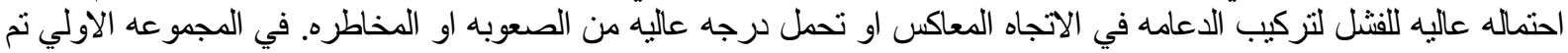

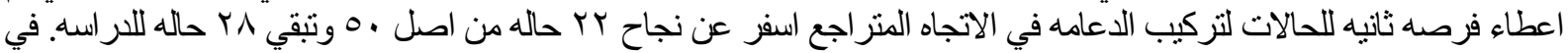

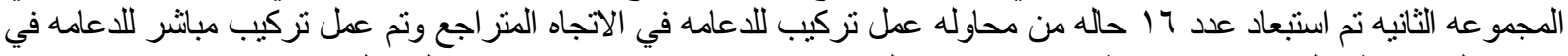

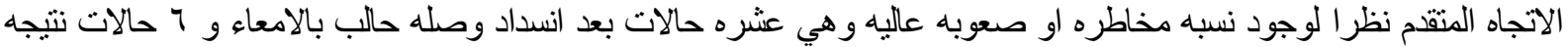

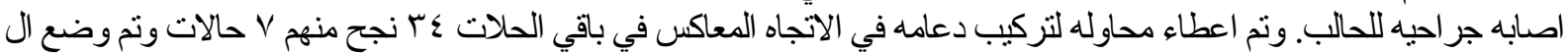

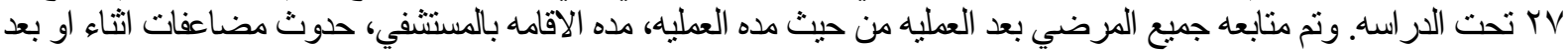

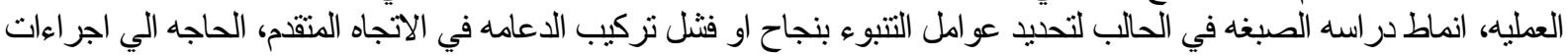

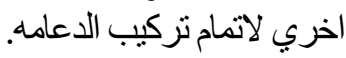

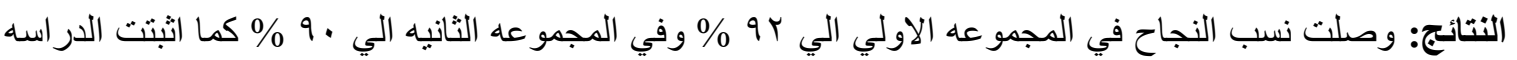

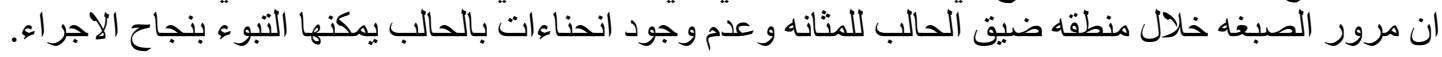
الخلاصة: تدعيم الحالب في الاتجاه المتقدم بديل جيد في حالة عدم نجاحة او صعوبتة في الاتجاة المتر اجع. 